Maurits van den Boogert,

\title{
Aleppo Observed: Ottoman Syria Through the Eyes of Two Scottish Doctors, Alexander and Patrick Russell (Studies in the Arcadian Library),
}

The Arcadian Library in association with Oxford University Press, 2010, 256 s., ISBN: 978-019-9588-56-5

Avrupa'da 17.-18. yüzyıllarda daha etkin bir çerçevede şekillenen ve bilimsel devrimin oluşumunda önemli katkılar yapan Respublica Literaria, dönemin akademileriyle birlikte çalışan bir çeşit sınır tanımayan bilim insanları cumhuriyeti mahiyetinde iş görmüştür. Evren ve doğayla ilgili tükenmez bir meraka ve araştırma ruhuna sahip olan bu bilim insanları, dönemin üniversitelerinin hâlâ devam eden skolastik eğitim anlayışları dolayısıyla genellikle akademilerde bir araya gelmişler veya bazen gündüz çalıştıkları işlerden sonra özellikle dolunayın olduğu geceler bir araya gelerek - çünkü dolunayın güçlü ışığı sayesinde bir araya gelebilmeleri nedeniyle kendilerini "Dolunay Cemiyeti" diye adlandırmışlardı doğanın bilinmeyen yönlerini keşfetmek için çaba sarfetmişlerdir. Bazen de yaşadıkları çevreye göre çok farklı ve zorlu coğrafya, iklim ve kültürel yaşam tarzının meydan okumalarına aldırmaksızın uzak bir çevrede ve doğal ortamlarda gözlem ve deneyimin peşinde koşmuşlar ve sayısız zorluk ve meşakkatlerin üstesinden gelerek hangi konuyla veya alanla uğraşmışlarsa onunla ilgili doğru bilgiyi, en azından dönemleriyle ilgili en doğru bilgiyi keşfetmek için gayret göstermişlerdir. İlk kurulan akademilerden Londra'daki Royal Society'nin ambleminde bulunan Nullius in verbal Hiç kimsenin sözüne bağll kalmadan düsturu, dönemindeki otoritelerin nüfuzunu sorgulamayı ve onlardan duyulan veya eserlerinden okunan her sözün veya iddianın, gözlem ve deneyime dayanarak elde edilen gerçeklikle teyit edilmesini öngören bu dönemle birlikte modern çağın bilim insanının en temel özelliği de böylece daha belirgin hale gelmiştir.

18. yüzyıl bilim insanlarından bir tanesi de, hatta ikisi şüphesiz, 18. yüzyıl dünyasında Osmanlılar'ın en büyük üç şehrinden biri olan Halep’te uzun yıllar yaşayan Russell kardeşlerdir. İskoç Aydınlanması’nın şekillendiği bir dönemde tıp alanındaki çalışmalarıyla katkıda bulunan ağabey Alexander Russell, Edinburgh'da, daha sonra Royal Medical Society of Edinburgh'a dönüşecek 1752'deki gayr-1 resmi ilk tıp cemiyetinin kurucuları arasında yer almışır. The Natural History of Aleppo başlığıyla 1756'da Alexander Russell (1715-1768) tarafından Halep'in daha çok doğal tarihi, ancak yer yer sosyal ve kentsel tarih konusunda önemli bilgiler ve 
OSMANLI ARAŞTIRMALARI

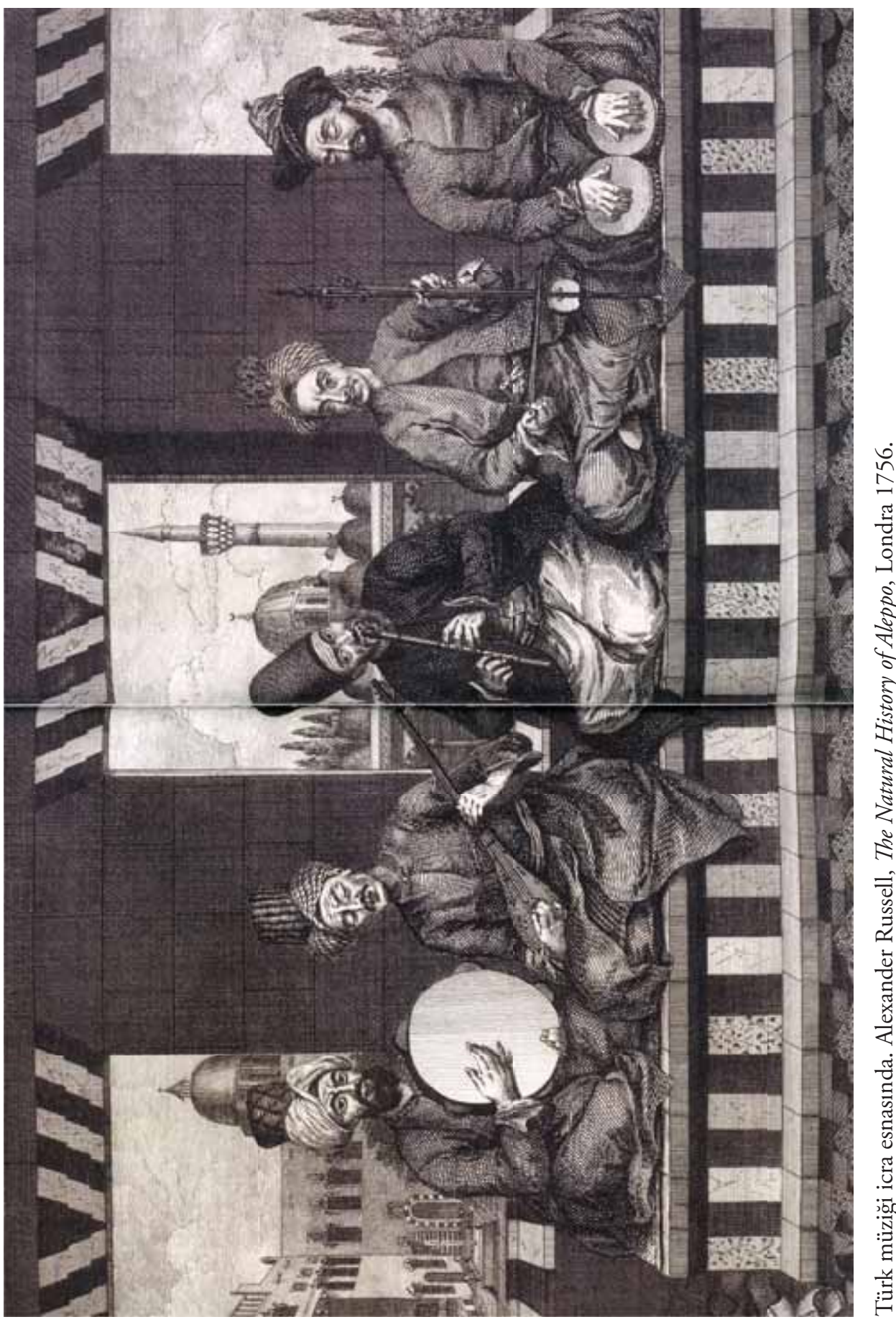


çeşitli çizimler içerecek şekilde hazırlanan bu kitabın ilk nüshası piyasada hızla tükenmiş, 18. yüzyıl boyunca birçok baskısı tekrarlanmış, ünü okuyucular arasında hızla yayılmıştır.

Alexander Russell, 1736'da Londra'da doktorluk eğitimini tamamladıktan sonra Halep'e gitmiş ve 1740 'da buradaki bir İngiliz fabrikasında doktor olarak istihdam edilmişti. Tıp alanındaki bilgi ve becerisi sayesinde şehrin eşrafının ve yöneticilerinin dikkatini çeken Russell, kısa zamanda Halep başhekimliğine getirilmişti. 1753 'te Londra'ya dönüşüne kadar görevde kalmış, bu esnada 1750 'de tıp eğitimini tamamladıktan sonra yanına gelen üvey kardeşi Patrick Russell (1726-1805) onun görevini üstlenmişti. 18 yıl Halep’te hekimlik yaptığı süre içinde büyük kardeşinin hazırladığı kitaba pek çok notlar eklemiş, dönemindeki çeşitli olaylara yer vermiş, örneğin 1760-1762 yılları arasında Halep'te patlak veren veba salgını hakkında dikkat çekici bilgiler kayda geçmiştir. Ağabeyi Russell 1768 'de öldükten sonra da çeşitli notlarla ve çizimlerle geliştirdiği ve zenginleştirdiği Natural History of Aleppo'nun gözden geçirilmiş nüshasını Patrick Russell, 1794'de tekrar yayınlamıştır. Her ikisinin de Royal Society'nin üyesi olduğu bilinmektedir. Russell kardeşler hem başarılı birer hekim hem de dikkatli doğa bilimcisi olmuşlardır. Her ikisinin de Halep’teki sosyal ve kültürel hayata özel ilgi gösterdiği, ortak çalışmalarından anlaşılmaktadır. Patrick Russell'in özellikle Halep'teki kültürel hayatıyla ilgili dikkatli incelemeler yapmış, şehirdeki sahaflardan ve kitapçılardan pek çok yazma eser toplamış - Osmanlı dünyasına gelen bu dönemin Avrupalı seyyahlarının tipik bir tutumu olmuştur -, İngiltere'ye döndüğünde bu kitap koleksiyonunu beraberinde götürmüş ve Avrupa'daki Osmanlı veya İslâm dünyasıyla ilgili çalışmalara dikkate değer katkıda bulunmuştur. Alexander Russell ise bazen Halep kadısı ve serdârı gibi şehrin önde gelenlerini bazen de halktan insanları tedavi ettiğini notlarından öğreniyoruz.

Bütün bu kıymetli bilgileri ve çok daha fazlasını, az önce adı geçen eser ve müellifleri hakkında modern bilimin şekillenmeye başladığı eşikte bir kez daha beliren temel tavır ve tutumlarla, özen, dikkat, merak, ciddiyet ve keyifle inceleyen Maurits van den Boogert'ın Aleppo Observed adlı kitabında rastlamak mümkündür. Avrupa aklının, uzun yıllar bir yandan içe hapsedilmenin, öte yandan yanlış ve yanıltıcı bilgi kaynaklarının getirdiği - Descartes' in 17.yüzyıldaki bunalımını düşünelim - bir tepkiyle doğaya ve fizik dünyaya büyük coşku, heyecan ve hayretle açılmaya başladığı; gözlemin daha ayrı, ayrıntılı ve geniş bir şekilde ortaya çıktığı bir zamanın mizacını başarılı bir şekilde araştıran yazar, 
Russell kardeşlerin hazırladığı eserdeki bilimsel bilgileri ve kaynaklarını, müelliflerin hayat hikayelerini, kendi kültür ve coğrafyasından uzaklarda yaşayan insanların dini gelenek, eğlence ve kültürleriyle birlikte şehir yaşamlarını adeta katılımcı bir antropolog gibi rahatsı etmeden ve incitmeden tetkik etmeye; doğal ortamlarını, bitki ve çiçek türlerine, kuş ve balık çeşitlerine varıncaya kadar pek çok ince ayrıntıya ve bu ayrıntının arkasındaki dikkatli gözleme özenle nüfuz eder.

Kitabını iki bölüme ayıran Maurits van den Boogert, birinci bölümde Russell kardeşlerin biyografilerine yer vermiş, ikinci bölümde ise Halep şehrini, doğal yapısını, tıp hayatını ve Osmanlı toplumsal yaşam düzenini ve Arap kültürünü incelemiştir. Halep’teki tıp ve sağlık hayatından önemli kesitler veren yazar, 17. ve 18. yüzyıl Avrupalı hekimlerin Osmanlı hekim meslektaşlarına göre kendilerini nasıl daha üstün gördüklerini ifade ederken, bu durumun Osmanlı tıp hayatından öğrenme kapılarını kapatmalarına yol açtığını vurgular. Örneğin bu dönemde vebaya göre daha sık ve çok daha yaygın olarak ortaya çıkan ölümcül çiçek hastalığıyla, Osmanlı hekimlerinin geliştirdikleri aşıyla üstesinden gelme deneyimini kaçırdıklarına parmak basar. Osmanlı tıp tarihi konusu, hâlâ pek çok noktanın keşfedilmesini bekleyen sayısız ince ve esrarlı unsur ve sorularla doludur. Türkçe yayınlanan eserler arasında, Osmanlı tıp tarihi konusu üzerinde önemli emekler veren Süheyl Ünver’in çalışmalarının yanı sıra Aykut Kazancıgil'in Bedizel Zülfikar ile birlikte modern dönemde Osmanlı tıbbının kurucu isimlerinden Şânizâde hakkında hazırladıkları 19. Yüzyılda Osmanlı Imparatorluğunnda Anatomi adlı eser zikredilebilir. IRCICA'nın 2008'de 4 cilt halinde yayınladığı Osmanl Tibbi Bilimler Literatürü Tarihìnde, 1430 müellif-çevirmenin Osmanlı dünyasında 5607 kitap, risale, makale ve raporun varlığına rastladığımızı belirtmek gerekir. Miri Shefer-Mossenshon'un Ottoman Medicine, Healing and Medical Institutions 1500-1700 ${ }^{1}$ adlı eseri Russell kardeşlerin gözlemlerini ve Boogert'in analizlerini anlamada yardımcı olabilir.

Halep’in, modernite öncesi dönemde Osmanlı kültürüyle Arap dünyasının pek çok açıdan birbiriyle başarılı bir şekilde etkileşim yaşayarak sentezlendiği ve kaynaştığı noktalardan birisi olduğuna şüphe yoktur. Bu ifade, özellikle farklı yaşam tarzlarının, dini inançların, yemek kültürlerinin ve sokaklarında konuşulan dillerin aynı şehir kültürü içinde sosyalleşerek birbirleriyle kaynaşmasını içermektedir. 1989'da Halep üzerinde çıkardığı The Middle East on the Eve of

I Albany: SUNY 2009. Bu çalışma Bülent Üçpunar tarafından Türkçe’ye çevirilmiş ve 20I4'de Kitap Yayınevi yayınları arasında çıkmıştır. 


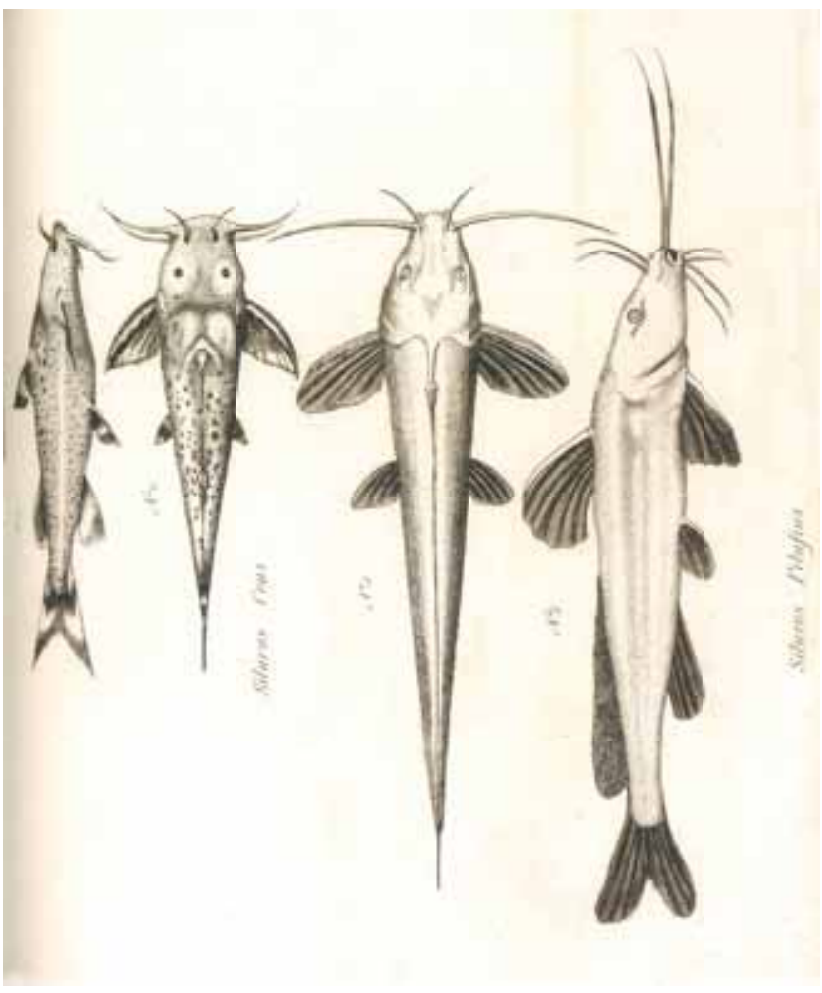

Alexander Russell'in, Peter Collinson'a gönderdiği bir mektupta bahsettiği "Halep'in bilinmeyen dört balığı". Bilinen ilk hakemli dergi Philosophical Transactions of the Royal Society'nin 1755 sayıs (29/ s.445-9). Aynı zamanda The Natural History of Aleppo'nun ilk baskısı.

Modernity: Aleppo in the Eigteenth Century ${ }^{2}$ adlı kitabından sonra çalışmalarına ara vermeden hâlâ çeşitli arşivlerde büyük emekle çalışan Abraham Marcus'un, yakında yine Halep hakkında önemli başka bir eseri ortaya koymasını ilgiyle beklemekteyiz. Son zamanlarda arşiv araştırmaları için İstanbul'a sıklıkla gelen Marcus'un, bir sohbet anımızda, Osmanlı Halebi üzerinde dünyanın farklı ülkelerinde çalışan araştırmacıların katılımıyla, 2014'de Montreal'da bir araya gelip iki günlük Requiem for Ottoman Aleppo toplantısını nasıl gerçekleştirdiklerini içi acıyarak anlatışını hiç unutmam. Marcus'un ailesi de uzun yıllar önce Halep'ten Amerika’ya göç edenler arasında yer almıştı, ancak daima Halep’e bağlı kalmışlard.. Bu "Requiem”e Marcus'la birlikte Charles Wilkins, Stefan Winter, Bernard Heyberger, Sylvain Cornac, Stefan Knost, Elyse Semerdjian, Marco Salati, Mary Momdjian, Nicolas Jodoin, Mafalde Ade ve Heghnar Watenpaugh gibi araştırmacılar da katılmıstı.

2 New York: Columbia University Press, 1989. Mehmet E. Baş tarafından Türkçe’ye de çevrilmiş ve Küre Yayınları arasında 20ı3'de çıkmıştır. 
Maurits van den Boogert, Russell kardeşlerin Natural History of Aleppo hakkında, dönemindeki çeşitli dergilerde tanıtım ve eleştirisinin yapıldığını, ancak gerek dönemindeki veya gerek daha sonraki bilim insanları ve eleştirmenlerin bu kitapta geçen toplumsal olayların veya bilimsel olguların güvenilirliğini sarsacak bir yorumuna şimdiye kadar rastlanmadığını ifade etmektedir. Gerek bağlam analizi, gerekse içerik analizi açısından başarılı bir kitap çalışması ortaya koyan yazar, hem bilim ve kent tarihi ve hem karşılaştırmalı entelektüel tarih konularında araştırma yapanlar açısından ellerinde keyifle okuyacakları ve inceleyecekleri bir eser ortaya koymuştur. Russell kardeşler nasıl ki seyahat ettikleri ülke ve şehirlerin veya bölgelerin insanlarının yaşamları ve kültürlerinin yanı sıra doğasını, bitki örtüsünü, nehirlerinde veya göllerinde barındırdıkları balık çeşitlerine varıncaya kadar pek çok unsuru itinayla ve dikkatle sistematik bir şekilde gözlemlemiş ve incelemişlerse, Aleppo Observed un yazarı da onların hayatlarını, notlarını ve çalışmalarını aynı titizlikle ve özenle incelemiş ve bizi, karşısında saygıyla eğilmeye mecbur bırakan bir eser ortaya koymuştur.

\section{Seyfi Kenan}

Marmara Üniversitesi

Nükhet Varlik,

\section{Plague and Empire in the Early Modern Mediterranean World: the Ottoman Experience, 1347-1600,}

New York: Cambridge University Press, 2016, 336 pp., ISBN 978-110-7013-38-4.

Most visitors will be struck by the multitude of cats that seem to dominate the cityscape of modern Istanbul. Despite whatever municipal attempts to control the feline population have been carried out in the past and present, one senses that Istanbulites regard cats not as nuisances but rather as benign and welcome components of the urban fabric. The ubiquity of street cats is often anecdotally-linked to the observation that in comparison with comparable world cities such as New York, Istanbul is relatively rodent-free. This mundane aspect of life in Istanbul today attains new meaning alongside a reading of Nükhet Varlık's groundbreaking Plague and Empire in the Early Modern Mediterranean World. In her discussion of 